\title{
Axial stretching of extremity artery induces reversible hyperpolarization of smooth muscle cell membrane in vivo
}

\author{
E. Monos ${ }^{1,2}$, G. Raffai ${ }^{1}$, S. J. Contney ${ }^{2}$, W. J. Stekiel ${ }^{2}$, \\ A. W. Cowley Jr. ${ }^{2}$ \\ ${ }^{1}$ Institute of Human Physiology and Clinical Experimental Research, \\ Semmelweis University, Budapest, Hungary \\ ${ }^{2}$ Department of Physiology, Medical College of Wisconsin, Milwaukee, Wisconsin, USA
}

Received: February 5, 2002

Accepted: March 20, 2002

\begin{abstract}
Circumferential stretch due to increases in pressure induces vascular smooth muscle cell depolarization and contraction known as the myogenic response. The aim of this study was to determine the in vivo effects of axial-longitudinal stretch of the rat saphenous artery (SA) on smooth muscle membrane potential (Em) and on external diameter. Consecutive elongations of the SA were carried out from resting length $\left(\mathrm{L}_{0}\right)$ in $10 \%$ increments up to $140 \% \mathrm{~L}_{0}$ while changes in membrane potential and diameter were determined in intact and de-endothelized vessels. Axial stretching resulted in a small initial depolarization at $120 \%$ of $\mathrm{L}_{0}$ followed by a progressive 20 to $33 \%$ hyperpolarizaion of vascular smooth muscle between $130 \%$ and $140 \%$ of $\mathrm{L}_{0}$. At $140 \%$, an average maximal $10.6 \mathrm{mV}$ reversible hyperpolarization was measured compared to $-41.2 \pm$ $0.49 \mathrm{mV} \mathrm{Em}$ at $100 \% \mathrm{~L}_{0}$. De-endothelialization completely eliminated the hyperpolarization to axial stretching and augmented the reduction of diameter beyond $120 \% \mathrm{~L}_{0}$. These results indicate that arteries have a mechanism to protect them from vasospasm that could otherwise occur with movements of the extremities.
\end{abstract}

Keywords: arterial strain, endothelium, smooth muscle, vascular myogenic response

Correspondence should be addressed to

Emil Monos

Institute of Human Physiology and Clinical Experimental Research

Semmelweis University

H-1446 Budapest, P.O. Box 448, Hungary

Phone: (36-1) 210-6038

Fax: (36-1) 334-3162

E-mail: monos@elet2.sote.hu 
Tangential (circumferential) stretch induced by transmural pressure in arteries $(3-5,13,20)$ and veins $(1,12,15,18)$ elicits depolarization of the smooth muscle (VSM) cell membrane potential (Em) that is accompanied by an intrinsic myogenic increase in vascular tone. This response is endothelium independent and can be significantly augmented in response to long-term orthostatic pressure load in the limb veins $(1,16,21)$. Similar augmentation occurs in arteries and veins in the early phase of arterial hypertension $(14,20)$ and in response to a noradrenergic stimulus $(6,18)$.

However, certain blood vessels, such as those in the heart (8) and in the extremities, are physiologically exposed not only to tangential stretch but also to axial (i.e. longitudinal) elongations. We have observed that extension of a limb from a full flexion position can alter the length of the saphenous vessels by substantially more than $20 \%$ in the rat (unpublished observation). In a previous study, we found that axial stretch of the in situ rat saphenous vein beyond its resting length caused endotheliumdependent hyperpolarization of the VSM Em and a concomitant suppression of the active tangential vascular tone (17). We proposed that this mechanism may serve to protect vessels from spasm when exposed to extreme physiological stretches. Since such responses have not been studied before in arteries, the present experiments were carried out to determine if a similar mechanism is operating in arteries.

Thus, the purpose of the present study was to determine whether incremental increases of axial stretch would hyperpolarize the VSM Em of the rat saphenous artery, and alter the active intrinsic myogenic tone. Further objectives were to study whether such responses depend on the presence of intact endothelium and to determine if they are reversible.

\section{Materials and Methods}

\section{Experimental animals}

Studies were performed in 7 male Sprague-Dawley rats $(347 \pm 10.9 \mathrm{~g}$ body wt) anesthetized with a combination of ketamine $\mathrm{HCl}$ (30 mg/kg; Aveco, Fort Dodge, IA) and pentobarbital sodium ( $25 \mathrm{mg} / \mathrm{kg}$; Anthony Products, Arcadia, CA). Anesthesia was maintained with occasional administration of supplemental doses appr. $10 \%$ of the initial dose.

\section{Preparation of the saphenous artery}

Vessel preparation and measurements were performed similar to that developed in an earlier study (17). In brief, anesthetized rats were placed on a temperature 
controlled double-walled platform constructed of polystyrene with minimal water and chemical absorption properties. The platform was mounted on a microscope stage that could be controlled in two dimensions. A $2-2.5 \mathrm{~cm}$ long segment of the saphenous artery (SA) was surgically exposed through a skin incision and superfused with $37^{\circ} \mathrm{C}$ physiological salt solution (PSS). The PSS was maintained at $\mathrm{pH} 7.3-7.4, \mathrm{pCO}_{2}$ 35-40 mm Hg, and $\mathrm{pO}_{2} 100-120 \mathrm{~mm} \mathrm{Hg}$. The composition of the PSS in mM was: 119 $\mathrm{NaCl}, 4.7 \mathrm{KCl}, 1.6 \mathrm{CaCl}_{2}, 1.17 \mathrm{MgSO}_{4}, 24.0 \mathrm{NaHCO}_{3}, 1.18 \mathrm{NaH}_{2} \mathrm{PO}_{4}, 0.026$ EDTA and 5.5 glucose. Special care was taken to minimize damage to the periadventitial connective tissue of the artery during the dissection process.

A specially constructed pair of miniature three-tined metal forks, the separation of which could be accurately controlled by a micromanipulator, was mounted on the animal platform (Fig. 1). The center tine of each fork was placed between the isolated adjacent saphenous vein (SV) and the SA segment, and the outer tines on the outer sides of each vessel. With this arrangement, the periadventitial connective tissue, and consequently the vessel segment, could be streched biaxially without causing axially asymmetric transverse distortions of the vessel wall. Either well-visualized side-branches or two strands from a silk suture glued to the vessel wall $8-10 \mathrm{~mm}$ apart, served as markers to measure the step increments of axial stretch. Baseline in situ vessel length $\left(\mathrm{L}_{0}\right)$ was defined as the shortest distance between the markers with no axial stretch or vessel folding. In order to maintain vessel length constant at a particular level of axial stretch during the time interval required for determination of the average Em value, the metal forks were carefully readjusted with the micromanipulator to compensate for an occasional tissue creep. The position of the extremity was maintained halfway between full extension and full flexion. A high resolution microscope eyepiece micrometer was used to measure $\mathrm{L}$ when stretching axially in $10 \%$ increments between 0 and $40 \%$.

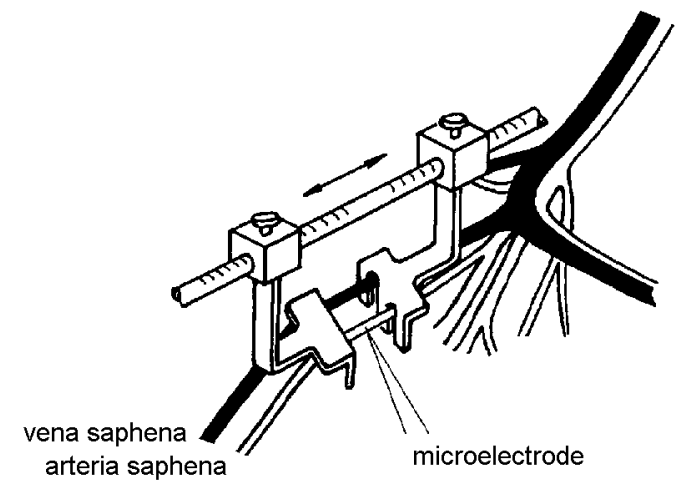

Fig. 1. Schematic drawing of the experimental arrangement. Three-tined metal forks mounted on a micromanipulator were applied to separate and axially stretch saphenous artery and vein segments in situ. Microelectrode was used to measure smooth muscle cell membrane potential 
Arterial pressure was monitored from the contralateral femoral artery in each experimental animal using a Gould-Statham P23 ID pressure transducer and a Grass polygraph.

\section{Measurement of VSM Em in situ}

A miniature silicon rubber-coated metal plate, rigidly fixed to the frame of the animal platform, was inserted under the artery. In order to minimize pulsation-elicited artifacts during measurements of Em values, one side of the artery wall was stabilized by insertion of a row of miniature tungsten pins adjacent to the vessel into the coat of silicon rubber on the metal plate. Thus, the wall of the SA, which rested against the pins, could move longitudinally but not laterally. A conventional short-tapered glass micropipette filled with $3 \mathrm{M} \mathrm{KCl}$ having appr. $1 \mu \mathrm{m}$ tip diameter and 60-100 $\mathrm{M} \Omega$ impedance was mounted on a silver-silver chloride active lead connected to a capacitycompensated biological amplifier (Mentor Instrument; Minneapolis, MN). Output signals were recorded in parallel on a Tektronix storage oscilloscope and a the Grass polygraph. One average $E m$ value was calculated at each selected vessel length, using the individual Em measurement data of five successful impalements of VSM cells made randomly from the adventitial side of the vessel. For a series of such successful impalements, max. 15-20 min period of time was required.

\section{Measurement of SA outer diameter (De)}

The SA De was measured optically by using a high-resolution microscope eyepiece micrometer with an accuracy of $5 \mu \mathrm{m}$.

\section{Experimental protocol}

To avoid neural influences, the saphenous vessels were locally sympathectomized by superfusing with PSS containing $10^{-6} \mathrm{M}$ phentolamine for 5 min followed with PSS containing 6-hydroxydopamine $(300 \mu \mathrm{g} / \mathrm{ml})$ for $20 \mathrm{~min}(20)$. Em and De measurements were made one-hour following washout using normal PSS (1 vessel/animal). Em and De were measured first in the denervated endothelium-intact artery segment at $\mathrm{L}_{0}$ and four consecutive $10 \%$ increases in vessel length, then again at $\mathrm{L}_{0}$ in order to check reversibility of the responses. The measurements were then repeated one hour after deendothelialization using air embolization. An air bolus was carefully introduced into the exposed SA segment via a 30 gauge needle inserted obliquely into its proximal end. 
Upon filling of about $1 \mathrm{~cm}$ length of the artery with the air bolus, the distal end of the vessel was quickly occluded and maintained in this stop-flow condition for $6 \mathrm{~min}$. At the end of this time, the air bolus was withdrawn from the proximal end via the needle, which was then removed. Normal blood flow was re-established by removal of the occluder. In separate vessel preparations, electron-microscopic examinations revealed that this techique completely removed the endothelial cell layer without damaging the VSM.

\section{Statistics}

Under both experimental conditions, data are shown as means \pm SE of the measured variable. Stats Plus computer software package was applied using analysis of variance with repeated measures to estimate the significance of differences between means. A $\mathrm{P}<0.05$ was regarded as significant.

\section{Results}

Initial values of arterial blood pressure $(123 \pm 5.0 \mathrm{~mm} \mathrm{Hg})$ and heart rate $(395 \pm$ $10.9 \mathrm{bpm}$ ) of the animals did not change significantly during the experiments.

\section{Effect of longitudinal stretch on Em of VSM cell in endothelium-intact SA}

As illustrated in Figure 2, at zero axial stretch $\left(\mathrm{L}_{0}\right) \mathrm{Em}$ averaged $-41.2 \pm 0.49 \mathrm{mV}$. The Em response to $10 \%$ step increases of axial length was biphasic, with a small but significant depolarization at $L_{20}(E m=-39.0 \pm 1.35 \mathrm{mV})$ relative to $L_{10}(E m=-42.3 \pm$ $0.55 \mathrm{mV}$ ), followed by a substantial $23 \%$ and a $33 \%$ hyperpolarization at $\mathrm{L}_{30}$ and $\mathrm{L}_{40}$ $(E m=-48.1 \pm 0.95 \mathrm{mV}$ and $-51.8 \pm 0.67 \mathrm{mV})$, respectively. After restoring the vessel length to $L_{0}$, the $E m$ returned back close to its initial value $(-39.3 \pm 0.35 \mathrm{mV})$.

\section{Effect of longitudinal stretch on Em of VSM cell in de-endothelialized SA}

Compared to intact vessels, VSM cell membrane was significantly less polarized at all levels of axial stretch, except $L_{20}$, in de-endothelialized SA, even at the $\mathrm{L}_{0}$ length. $(E m=-39.3 \pm 0.35 \mathrm{mV})$. There was even a tendency toward further depolarization at lengths beyond $L_{20}$ rather than the hyperpolarization, that was observed in endotheliumintact arteries (Fig. 2). 


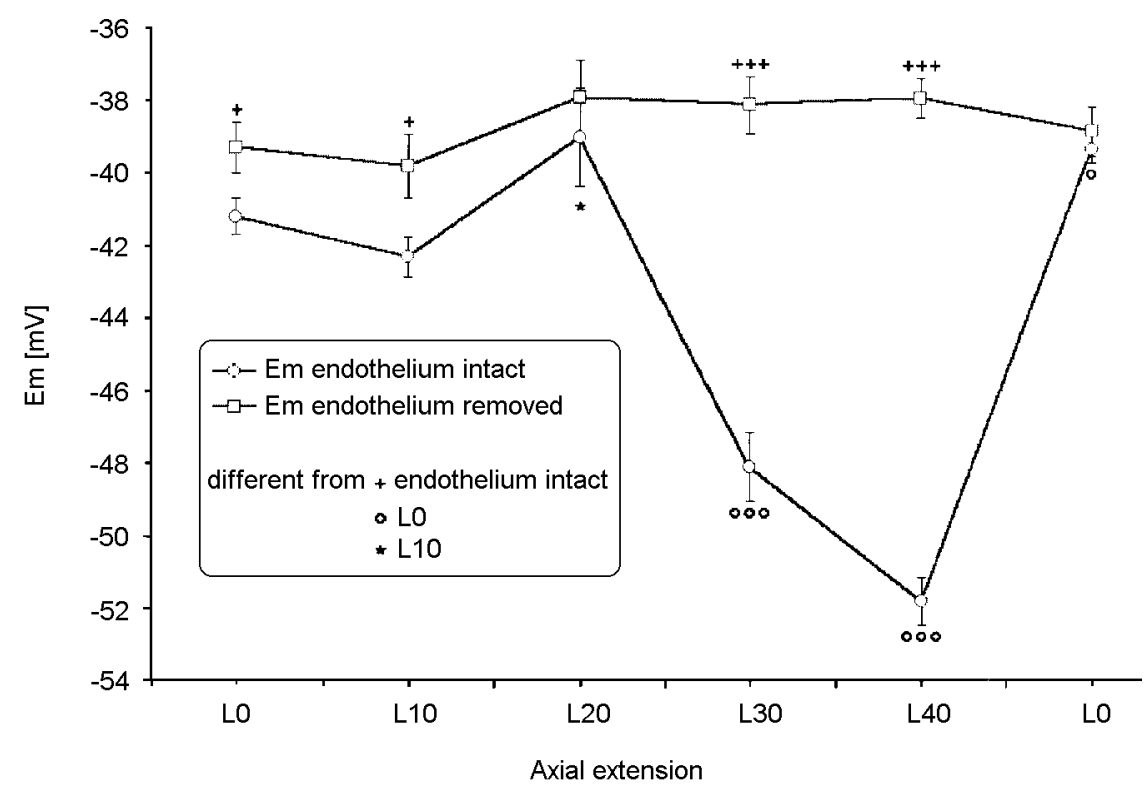

Fig. 2. Axial stretch evoked transmembrane potential (Em) responses of saphenous artery smooth muscle to stepwise elongations $\left(10 \%\right.$ increments from $\mathrm{L}_{0}$ to $\mathrm{L}_{40}$ and returning to $\left.\mathrm{L}_{0}\right)$ on intact $(0)$ and endothelium denuded (?) segments measured in situ. Note that on intact artery segments the changes in Em were reversible when returning the vessel length to $\mathrm{L}_{0}$ from $\mathrm{L}_{40}$. Data is expressed as mean $\pm \mathrm{SE}$

Changes in external diameter (De) of intact and de-endothelialized SA

during axial stretching

$D e$ of SA averaged $683 \pm 33.2 \mu \mathrm{m}$ at $L_{0}$ in intact vessels. The initial $10 \%$ elongation of the vessel resulted in an average $51 \pm 8 \mu \mathrm{m}$ diameter reduction. Further elongations of the vessel by $10 \%\left(\mathrm{~L}_{10}-\mathrm{L}_{20}, \mathrm{~L}_{20}-\mathrm{L}_{30}\right.$ and $\left.\mathrm{L}_{30}-\mathrm{L}_{40}\right)$ resulted in additional reductions of diameter $56 \pm 14.1,72 \pm 6.4$ and $59 \pm 4.9 \mu \mathrm{m}$, respectively as seen in Figure 3. De returned to initial values when the vessel length was set back to $\mathrm{L}_{0}$ $(680 \square\} 31.9 \mu \mathrm{m})$.

Stretch induced decreases in De were similar in de-endothelialized vessels with axial extensions between $110 \%$ to $120 \%$ of $\mathrm{L}_{0}(37.3 \pm 8.2$ and $59 \pm 9.5 \mu \mathrm{m}$, respectively) but were significantly enhanced with further extensions to 130 and $140 \%$ of $\mathrm{L}_{0}$ (91.1 \pm 14.5 and $80.3 \pm 14 \mu \mathrm{m}$, respectively) compared to the diameter change at $110 \% \mathrm{~L}_{0}$ (Fig. 3). 


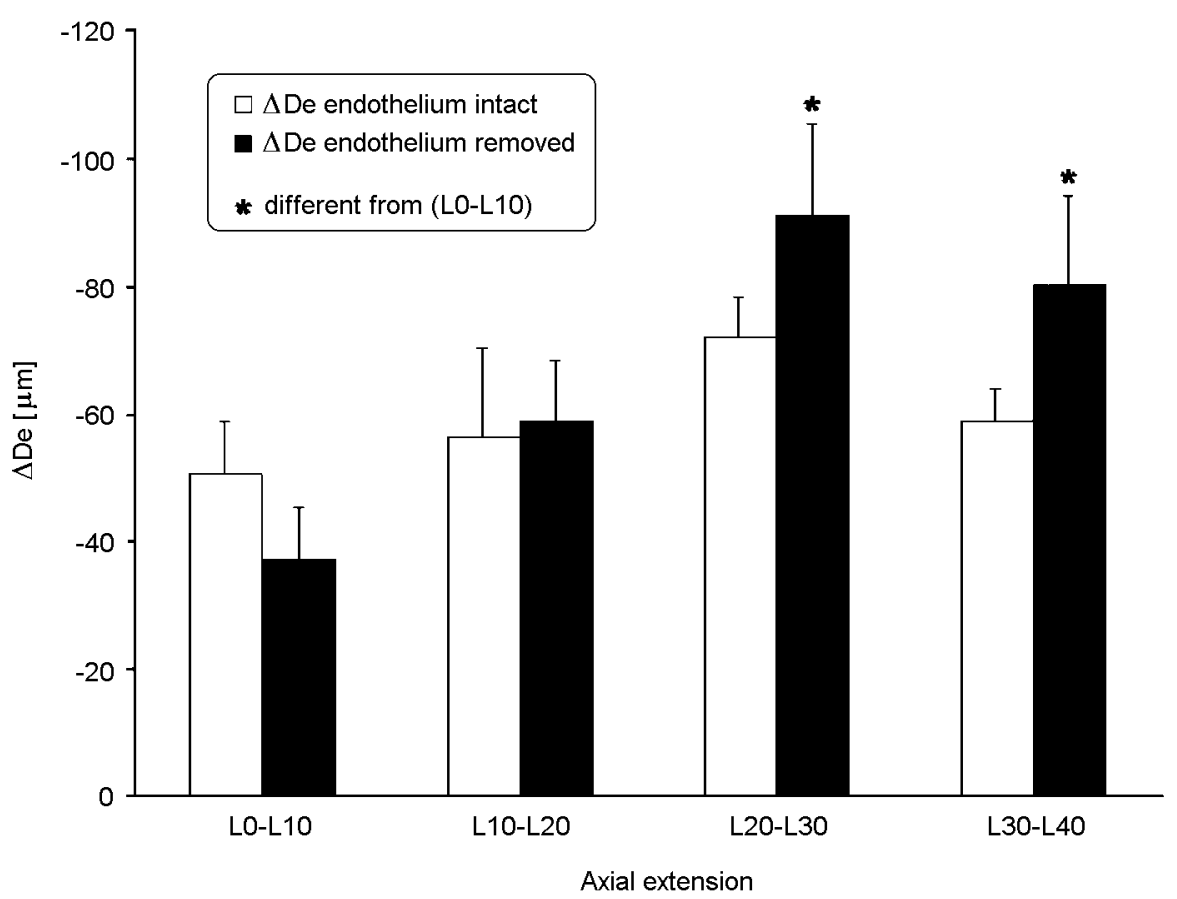

Fig. 3. Changes in external diameter $(\Delta \mathrm{De})$ of intact and endothelium removed segments of saphenous artery at different levels of stepwise axial elongations (10\% increments from $\mathrm{L}_{0}$ to $\mathrm{L}_{40}$ ) measured in situ. When endothelium was removed $\Delta \mathrm{De}$ was significantly larger between $\mathrm{L}_{20}-\mathrm{L}_{30}$ and $\mathrm{L}_{30}-\mathrm{L}_{40}$ compared to $\mathrm{L}_{0}-\mathrm{L}_{10}$. Data is expressed as mean $\pm \mathrm{SE}$

\section{Discussion}

The major observation in this study was that increasing the length of the saphenous artery above the estimated resting level in vivo resulted in an endothelium dependent VSM hyperpolarization that attenuated the stretch induced reductions of diameter. This vascular response was reversible and did not depend on innervation.

These changes in bioelectrical and biomechanical properties of the artery related to axial stretch conform with responses of rat saphenous veins that we reported in an earlier study (17). Thus, this mechanism is present in both arteries and veins and may serve a meaningful role in protecting against vessel spasms during situations of large axial stretches. These responses are reversible, with the extended artery returning to its initial, fully relaxed length, and membrane potential. 
The estimated in vivo "resting" axial length of the large saphenous vessels is by about $20 \%$ above the fully relaxed, somewhat compressed length. This extension ratio further increases by about $10 \%$ when the extremity is stretched during usual locomotor activity of the animal, and approaches $40 \%$ total extension in extreme situations (unpublished observation by E. Monos and S. J. Contney).

We found in earlier studies that local chemical denervation of blood vessels, such as the saphenous artery and vein of the rat, resulted in a moderate but statistically significant hyperpolarization of the VSM Em, the magnitude of which represents the sympathetic component of Em (16). Although it was not expected that local chemical denervation would cause substantial changes in Em-responses of the saphenous artery to axial stretch (17), denervation was carried out in this study to prevent any unexpected neural influence on the SA responses. The results of the present study provide evidence that the stretch induced active $E m$ and De responses were intrinsic to the vasculature. Such intrinsic response could be initiated for instance by ATP released from perivascular nerves resulting in hyperpolarization of arterial VSM cells via endothelium dependent mechanism (22).

The cause of VSM Em hyperpolarization in SA remains to be determined. It is possible that with narrowing the vessel caliber due to the axial stretch, an elevated pressure head occurs along the narrow extended section, as seen in a Piezometer (7). This would increase the linear blood flow velocity gradient and consequently enhances shear rate on the endothelium surface. There is strong evidence that such shear forces, as natural stimuli, stimulate the endothelium to release nitric oxide which hyperpolarizes and relaxes the VSM $(2,11,19)$. Preliminary studies in our laboratory using laserdoppler flowmetry (Periflux, PF3), together with direct volume flow measurements have suggested, that $30-40 \%$ local axial extension of SA results in a substantial elevation of the linear blood flow velocity in the elongated vessel segment while volume flow velocity decreases only slightly (unpublished obstervations by R. Roman and E. Monos).

It is noteworthy that even the largest axial stretch applied in this study did not cause significant VSM Em depolarization in the de-endothelized arteries. This was not seen in venous segments where depolarization did occur at this level of stretch (17). We presume, that sustained elongation of the artery induces substantial rearrangement of the anisotropic connective tissue network structure of the vascular wall (10) together with the VSM cells in a way that they are not stretched significantly, at least not in the external (i.e. adventitial) VSM cell layers of the SA media where probably the most Em measurements were made in our experiments. This assumption is consistent with the observations of Hill et al. (9) who found that sustained longitudinal stretching of rat cremaster arterioles in vitro resulted in only a short transient increase of intracellular Ca-ion concentration. 
In conclusion, this study provides evidence that the in vivo longitudinal stretching of an extremity artery segment well beyond the resting length may induce hyperpolarization of its VSM cell Em when the endothelium is present, and a tendency to decrease in the active tone of vessel. This response is intrinsic to the intact vascular wall. Taking into account that maximal extension and flexion of an extremity is accompanied with a substantial lengthening of its vessels running in axial direction, these changes in electrical and biomechanical properties of the artery may reflect an intrinsic mechanism of the vascular wall that protects the vessels from spasm when they are axially overstreched.

\section{Acknowledgements}

This work was supported by National Science Foundation - MTA Grant Int-890894 (Hungary), and by OTKA T-30245 and ETT 149/2000 Hungarian Grants, and by PO1-HL29587.

\section{REFERENCES}

1. Bérczi V, Greene AS, Dörnyei G, Csengődy J, Hódi G, Kádar A, Monos E: Venous myogenic tone: studies in human and canine vessels. Am. J. Physiol. Heart Circ. Physiol. 263, H315-H320 (1992)

2. Busse R, Fleming I: Pulsatile stretch and shear stress: physical stimuli determining the production of endothelium-derived relaxing factors. J. Vasc. Res. 35, 73-84 (1998)

3. Davis MJ, Hill MA: Signaling mechanisms underlying the vascular myogenic response. Physiol. Rev. 79, 387-423 (1999)

4. Davis MJ, Meininger GA, Zawieja DC: Stretch-induced increases in intracellular calcium of isolated vascular smooth muscle cells. Am. J. Physiol. Heart Circ. Physiol. 263, H1292-H1299 (1992)

5. Davis MJ, Donovitz JA, Hood JD: Stretch-activated single-channel and whole cell currents in vascular smooth muscle cells. Am. J. Physiol. Cell Physiol. 262, C1083-C1088 (1992)

6. Dörnyei G, Monos E, Kaley G, Koller Á: Myogenic responses of isolated rat skeletal muscle venules: modulation by norepinephrine and endothelium. Am. J. Physiol. Heart Circ. Physiol. 271, H267-H272 (1996)

7. Folkow B, Neil E (1971): Circulation. Oxford University Press, New York, pp. 59-61.

8. Frobert O, Mikkelsen EO, Bagger JP: The influence of transmural pressure and longitudinal stretch on $\mathrm{K}^{+}$- and $\mathrm{Ca}^{2+}$-induced coronary artery constriction. Acta Physiol. Scand. 165, 379-85 (1999)

9. Hill MA, Zou H, Davis MJ, Potocnik SJ, Price S: Transient increases in diameter and $\left[\mathrm{Ca}^{2+}\right]_{\mathrm{i}}$ are not obligatory for myogenic constriction. Am. J. Physiol. Heart Circ. Physiol. 278, H345-H352 (2000)

10. Hudetz AG, Monos E: Characterization of anisotropic elastic properties of the arteries by exponential and polynomial strain energy functions. Acta Physiol. Acad. Sci. Hung. 57, 111-122 (1981)

11. Koller Á, Kaley G: Shear stress dependent regulation of vascular resistance in health and desease: role of endothelium. Endothelium 4, 247-272 (1996)

12. Kuo L, Arko F, Chilian WM, Davis MJ: Coronary venular responses to flow and pressure. Circ. Res. 72, 607-615 (1993)

13. Kuo L, Chilian WM, Davis MJ: Coronary arteriolar myogenic response is independent of endothelium. Circ. Res. 66, 860-866 (1990) 
14. Monos E, Kauser K, Contney SJ, Cowley AW Jr, Stekiel WJ (1991): Biomechanical and electrical responses of normal and hypertensive veins to short-term pressure increases. In: Cellular Apects of Hypertension, eds Bruschi G, Borghetti A, Springer, Berlin Heidelberg New York, pp. 51-57.

15. Monos E, Contney SJ, Cowley AW Jr, Stekiel WJ: Electrical and mechanical responses of rat saphenous vein to short-term pressure load. Am. J. Physiol. Heart Circ. Physiol. 256, H47-H55 (1989)

16. Monos E, Contney SJ, Cowley AW Jr, Stekiel WJ: Effect of long-term tilt on mechanical and electrical properties of rat saphenous vein. Am. J. Physiol. Heart Circ. Physiol. 256, H1185-H1191 (1989)

17. Monos E, Contney SJ, Dörnyei G, Cowley AW Jr, Stekiel WJ: Hyperpolarization of in situ rat saphenous vein in response to axial stretch. Am. J. Physiol. Heart Circ. Physiol. 265, H857-H861 (1993)

18. Monos E, Bérczi V, Nádasy G: Local control of veins: biomechanical, metabolic, and humoral aspects. Physiol. Rev. 75, 611-666 (1995)

19. Rubanyi GM, Freay AD, Kauser K, Johns A, Harder DR: Mechanoreception by the endothelium: mediators and mechanisms of pressure- and flow-induced vascular responses. Blood Vessels 27 , 246-257 (1990)

20. Stekiel WJ, Myers K, Monos E, Lombard JH (1988): Stretch-dependent tone in small mesenteric and gracilis muscle arteries from spontaneous (SHR) and volume-expanded hypertensive rats. In: Resistance Arteries, eds Halpern W, Pelgram BL, Brayden JE, Mackey K, McLaughlin MK, Osol G, Perinatology, Ithaca, pp. 347-358.

21. Szentiványi M Jr, Bérczi V, Hüttl T, Reneman RS, Monos E: Venous myogenic tone and its regulation through $\mathrm{K}^{+}$channels depends on chronic intravascular pressure. Circ. Res. 81, 988-995 (1997)

22. Thapaliya S, Matsuyama H, Takewaki T: ATP released from perivascular nerves hyperpolarizes smooth muscle cells by releasing an endothelium-derived factor in hamster mesenteric arteries. J. Physiol. Lond. 521, 191-199 (1999) 